\title{
A CORREÇÃO DE DECISÕES JUDICIAIS PELO PODER LEGISLATIVO
}

\author{
LEONARDO PIETRO ANTONELLI*
}

\begin{abstract}
1. Delimitação do Tema - 2. Formas de Correção - 3. Breve e Peculiar Histórico Corretivo Constitucional Brasileiro - 4. O STF e a Impossibilidade de Aliquotas Progressivas - 5. Conclusões - 6. Referências Bibliográficas.
\end{abstract}

“A correção de decisões judiciais mediante lei superveniente é, todavia, freqüente, podendo-se falar de um permanente jogo de xadrez entre Congresso e Suprema Corte, no qual aquele logra dar sempre o xeque mate."

Karl Loewenstein, 1959

\section{Delimitação do Tema}

O vocábulo contradição (do latim, contradictio) é usualmente utilizado em direito tributário quando duas ou mais normas são incoerentes, antinômicas ou incompatíveis entre si.

Nesses casos, o interprete e, no particular, o juiz, utiliza-se de formas clássicas para a sua superação, v.g. prevalência da norma posterior sobre a anterior de mesma natureza (lex posterior derogat priori), preferência da norma de nível superior em relação à de nível inferior (lex superior derogat priori), e predominância da norma especial sobre a de caráter geral (lex specialis derogat generali).

1 LOEWENSTEIN, Karl apud MENDES, Gilmar Ferreira. O Poder Executivo e o Poder Legislativo no Controle de Constitucionalidade: Cadernos de Direito Tributário e Finanças Públicas, São Paulo: Revista dos Tribunais, n. 20, 1997, p. 20.

* Advogado no Rio de Janeiro, Pós-Graduado em Direito Tributário pela Universidade Estácio de Sá, Mestrando em Direito Tributário pela Universidade Cândido Mendes, Membro da International Fiscal Association - IFA, Associação Brasileira de Direito Financeiro - ABDF e Associação Brasileira de Direito Tributário - ABDT, colaborador das revistas Revista Dialética de Direito Tributário, Revista Legislativa do Senado Federal e COAD/ADV. 
Todavia, como bem ressaltado pelo eminente professor RICARDO LOBO TORRES, ao prefaciar o livro Contradições no Direito Tributário ${ }^{2}$ do também ilustre professor ADILSON RODRIGUES PIRES, é exatamente no campo das contradições de princípios, onde as fórmulas clássicas não resolvem o conflito, que torna-se, por vezes, dramático o enfrentamento pelo intérprete da quaestio ${ }^{3}$.

Acresça-se a isso a tradição positivista no País de só reconhecer a existência dos princípios quando eles aparecem formalmente no texto básico ${ }^{4}$.

Dentro desse contexto, surge o interesse do presente trabalho, tendo em vista que o legislador constituinte derivado promulgou, em 14.09.2000 (D.O.U.), a Emenda Constitucional 29/00, cuja alteração possibilita aos Municípios instituírem alíquotas progressivas de IPTU em razão do valor, localização e uso do imóvel. ${ }^{5}$

A antinomia, in casu existente, decorre do conflito entre a aplicação do princípio da capacidade contributiva versus o da igualdade.

BOBBIO assevera que quando dois princípios são igualmente aplicáveis ou conflitantes ocorre uma antinomia de valores. ${ }^{6}$

É bem verdade que há casos concretos onde a antinomia é meramente aparente, sendo desnecessária a correção, posto que sanável mediante a ponderação.

RICARDO LOBO TORRES, invocando a doutrina de LARENZ, CLAUS-WILHELM CANARIS, ROBERT ALEXY vaticina que a ponderação utilizável em determinadas situações faz com que o intérprete aplique o princípio com peso maior que outro, sem daí se poder concluir pela superioridade de qualquer deles. ${ }^{7}$

Acontece que, como se demonstrará, o E. SUPREMO TRIBUNAL FEDERAL encampou a doutrina que distingue os impostos em pessoais e reais ${ }^{8}$, afastando a

2 PIRES, Adilson Rodrigues. Contradições no Direito Tributário, Rio de Janeiro: Forense, 1999.

3 RICARDO LOBO TORRES ao prefaciar o livro de ADILSON RODRIGUES PIRES esclarece que é escassa a bibliografia brasileira sobre as contradições, ressaltando que a doutrina brasileira nos últimos anos ficou presa, em grande parte, aos princípios formais do estado de direito, máxime a legalidade, preocupando-se casuisticamente com questões meramente fiscais. Todavia, tece grandes elogios ao citado autor pelo fato de seu livro ter enfrentado a dramática antinomia entre os princípios, mormente da capacidade contributiva e do desenvolvimento econômico, que se aguçou ultimamente face a concessão generosa de incentivos fiscais e pelo alívio da tributação de ganhos de capitais, bem como pela problemática da aplicação do princípio da igualdade segundo entendimento do STF e legislativo.

4 TORRES, Ricardo Lobo. Normas de Interpretação e Integração do Direito Tributário. Rio de Janeiro: Renovar, 2000, p. 44.

5 “Art. $3^{\circ} \mathrm{O} \S 1^{\circ}$ do art. 156 da Constituição Federal passa a vigorar com a seguinte redação:

Art. 156.

$\S 1^{\circ}$ Sem prejuízo da progressividade no tempo a que se refere o art. $182, \S 4^{\circ}$, inciso II, o imposto previsto no inciso I poderá: (NR)

I - ser progressivo em razão do valor do imóvel; e (AC)

II - ter alíquotas diferentes de acordo com a localização e o uso do imóvel. (AC)"

6 Apud PIRES, Adilson Rodrigues. Contradições no Direito Tributário, Rio de Janeiro: Forense, 1999, p. 24.

7 TORRES, Ricardo Lobo. Normas de Interpretação e Integração do Direito Tributário. Rio de Janeiro: Renovar, 2000, p. 46.

$8 \mathrm{RE} \mathrm{n}^{\circ}$ 153771-0/MG, Relator Ministro MOREIRA ALVES, DJ de 05/09/97, STF (leading case 
progressividade de alíquotas, supostamente legitimada pelo princípio da capacidade contributiva previsto no art. $145, \S 1^{\circ}$ da Carta Magna ${ }^{9}$, uma vez que o referido imposto incide sobre o imóvel (res: coisa) e não sobre a pessoa do contribuinte.

Imposto real, segundo BERNARDO RIBEIRO DE MORAES, é aquele que "é calculado sem atender as condições pessoais do contribuinte, ou melhor, ignorando por completo a situação individual do contribuinte (o imposto grava uma riqueza dada ou uma situação da mesma maneira, qualquer que seja o sujeito passivo). Os imposto reais gravam o contribuinte tendo em vista apenas a matéria tributável, segundo seus caracteres objetivos especificos, independentemente das condições econômicas, jurídicas, pessoais ou de familia, relativas ao contribuinte. A alíquota tributária é fixada exclusivamente em função apenas das circunstâncias materiais da situação de fato prevista na lei". ${ }^{10}$

Não fosse, pelas características apontadas pelo ilustre tributarista, o IPTU, imposto notoriamente real, já atenderia em tese ao princípio da capacidade contributiva, uma vez que, havendo alíquotas uniformes, a imposição fiscal seria, naturalmente, automaticamente, proporcional à riqueza.

Em outras palavras, quanto mais valioso for determinado imóvel, proporcionalmente maior será o IPTU devido.

A proporcionalidade é da natureza dos impostos reais sobre o patrimônio (IPTU, ITBI, IPVA), cuja base de cálculo seja o valor de mercado do bem.

Precisa, portanto, é a constatação de RICARDO LOBO TORRES no seu Tratado de Direito Constitucional, Financeiro e Tributário ao concluir que a opção do legislador pela adoção de critérios progressivos ou regressivos nos impostos sobre o patrimônio, notadamente proporcionais, fere a igualdade. ${ }^{11}$

Assim sendo, se o legislador permite via Emenda Constitucional a adoção da progressividade no IPTU, ferir-se-ia a igualdade, uma vez que o imposto já é originalmente proporcional. Tal permissivo pode acarretar na desigualdade entre contribuintes que se encontram na mesma situação, v.g., inobstante proprietários de imóveis de idêntico valor venal, pelas distintas localizações (regiões) dos mesmos, terão que suportar ônus tributário diferenciado. ${ }^{12}$

IPTU); RE 234.105-3/SP, Relator Ministro CARLOS VELLOSO, Tribunal Pleno, unânime, DJ de $31 / 03 / 2000$ (leading case ITBI).

9 “Art. 145 -

$\S 1^{\circ}$ - Sempre que possível, os impostos terão caráter pessoal e serão graduados segundo a capacidade econômica do contribuinte, facultando à administração tributária, especialmente para conferir efetividade a esses objetivos, identificar, respeitando os direitos individuais e nos termos da lei, o patrimônio, os rendimentos e as atividades econômicas do contribuinte."

10 MORAES, Bernardo Ribeiro. Compêndio de Direito Tributário, v. 1, Rio de Janeiro: Forense, 1999 , p. 439.

11 TORRES, Ricardo Lobo. Tratado de Direito Constitucional, Financeiro e Tributário, v. III, Rio de Janeiro: Renovar, 1999, p. 335.

12 Utilizar-se-á, à guiza de ilustração a legislação do IPTU do Município do Rio de Janeiro, cuja progressividade em razão da área*, por ela outrora adotada, sequer poderia ser (re) instituída, mesmo sob a égide da nova ordo iuris promulgada, posto que nesta não prevista. 
Todavia, por amor ao debate, superando-se o vício congênito de constitucionalidade, não parece que determinado imóvel, ora utilizado como residência, outrora como comercial, possa ter o valor de mercado alterado em face do uso.

Como legitimar-se uma diferença de $133 \%$ (cento e trinta e três por cento) de

Com efeito, até o exercício de 1999 a Lei Municipal $691 / 84$ previa a progressividade de alíquotas de acordo com a área do imóvel, cuja variaçāo era de $0,15 \%$ (zero vírgula quinze por cento) até $3,50 \%$ (três e meio por cento).

Todavia, tendo em vista a declaração de inconstitucionalidade proferida pelo E. SUPREMO TRIBUNAL FEDERAL em face do citado diploma legal**, a municipalidade editou nova lei, in casu a de $\mathrm{n}^{\circ} 2.955$, de 29.12.99, objetivando afastar o litígio em relação aos exercícios 2000 e seguintes, verbis:

"Lei 691/84 com redação dada pela Lei 2.955/99:

Art. 67 -

I - Imóveis Edificados

1. Unidades Residenciais 1,20

2. Unidades Não-Residenciais 2,80

II - Imóveis Não-Edificados 3,50"

Portanto, no presente exercício, o referido Município tributa os imóveis de sua circunscrição em razão da utilização.

Sobre o thema, insta consignar que à época da edição das citadas leis, inclusive aquela atualmente vigente, não havia autorização constitucional para a fixação de alíquotas progressivas. Daí o flagrante vício de inconstitucionalidade, o qual não pode ser convalidado por emenda constitucional superveniente.

Neste preciso sentido, já se pronunciou o E. SUPREMO TRIBUNAL FEDERAL, na sessão plenária do julgamento da ADIN 2-1/DF, onde se acordou que o vício de inconstitucionalidade deve ser apurado em face da Constituição vigente à época da edição da lei que a desrespeita e não, no particular, sob a ótica da redação dada por emenda constitucional superveniente, verbis:

"A lei é constitucional ou não é lei. Lei inconstitucional é uma contradição em si. A lei é constitucional quando fiel à Constituição; inconstitucional, na medida em que a desrespeita, dispondo sobre o que the era vedado. O vicio da inconstitucionalidade é congênito à lei e há de ser apurado em face da Constituição vigente ao tempo de sua elaboracão. " (trecho da ementa grifamos)

* Lei Municipal $\mathrm{n}^{\circ} 2.080 / 93 \mathrm{c} / \mathrm{c}$ Lei $\mathrm{n}^{\circ} 2.687 / 98$ fixavam alíquotas variáveis de $0,15 \%$ a $3,50 \%$ em razão da área (com até $50 \mathrm{~m}^{2}$ - mínima; acima de $1001 \mathrm{~m}^{2}$ - máxima) e localização (por bairros - regiōes $\mathrm{A}, \mathrm{B}, \mathrm{C}$ e orla).

* $\mathrm{RE} \mathrm{n}^{\circ}$ 248.892-5/RE, Recorrente: Município do Rio de Janeiro; Recorrido: Clínica São Vicente S/A, Relator: Ministro MAURÍCIO CORRÊA, DJ de 31.03.2000:

“TRIBUTÁRIO. IPTU PROGRESSIVO. MUNICÍPIO DO RIO DE JANEIRO. ARTIGO 67 DA LEI N ${ }^{\circ}$ 691/84. PRECEDENTES.

1. É pacífica a jurisprudência desta Corte no sentido de que a progressividade do IPTU, que é imposto de natureza real em que não se pode levar em consideração a capacidade econômica do contribuinte, só é admissível, em face da Constituição Federal, para o fim extrafiscal de assegurar o cumprimento da função social da propriedade.

2. O artigo 67 da Lei $n^{\circ} 691 / 84$, do Município do Rio de Janeiro, que instituiu a progressividade do IPTU levando em conta a área e a localização dos imóveis - fatos que revelam a capacidade contributiva - não foi recepcionado pela Carta Federal de 1988.

3. Recurso Extraordinário não conhecido. 
IPTU/ano, para imóveis com idêntico valor venal, entretanto com utilizações diferentes, tal como ocorre atualmente, no Município do Rio de Janeiro (vide nota 11)?

Sobre o tema, o autor desse trabalho já se manifestou no artigo "IPTU e a Inconstitucionalidade das Alíquotas Progressivas", Revista Condomínio e etc., ano $2, \mathrm{n}^{\circ} 7$, out/nov/dez 2000, págs. 12-13, verbis:

“(..) suponhamos que eu seja proprietário de um imóvel que valha $R \$$ 100.000,00 localizado no Leblon e outro contribuinte seja proprietário de imóvel localizado na Pavuna, cujo valor venal é, segundo inclusive o próprio Município - uma vez que a guia do IPTU traz num de seus campos este valor - também $R \$ 100.000,00$. Porque exigir até 5 vezes mais IPTU de mim, se a capacidade contributiva de ambos os contribuintes é a mesma? Ora, se o valor de venda do imóvel é idêntico, o imposto tem que ser idêntico, uma vez que o tributo é real e incide sobre a propriedade. Quanto mais valoroso for o imóvel, naturalmente o contribuinte irá pagar mais imposto, todavia com uma alíquota única para todos" 13 .

Merece registro que, encampando, in totum, ao argumentos ora expendidos, foi obtido pelo subscritor do presente, perante o TRIBUNAL DE JUSTIÇA DO RIO DE JANEIRO, o primeiro acórdão no leading case que versava sobre a inconstitucionalidade da progressividade em razão da utilização do IPTU/2000 (Lei nova), verbis:

\footnotetext{
“AGRAVO DE INSTRUMENTO. Mandado de segurança impetrado no juízo fazendário para ser suspensa exigibilidade do crédito tributário, referente ao exercício de 2000 , em face de alíquota diferenciada na cobrança do IPTU. Entendimento jurisprudencial dominante, inclusive do STF, quanto à impossibilidade de progressividade do IPTU, excluída a hipótese do artigo 182, parágrafo $4^{\circ}$, inciso II, da Constituição Federal. Em face de tal entendimento correto é afirmar-se a presença do "fumus boni iuris" e do "periculum in mora" a possibilitar a concessão de liminar. Decisão que se reforma." 14
}

Logo, $d . v$., não se trata de antinomia aparente, cuja aplicação, mediante ponderação, do princípio da igualdade (aliás, corolário da capacidade contributiva) resolveria a contradição.

Com efeito. Sendo a progressividade sub-princípio da capacidade contributiva, há típico conflito entre princípios.

Permanece a quaestio iuris: seria, pois, constitucional a EC 29/00?

13 ANTONELLI, Leonardo Pietro. IPTU e a Inconstitucionalidade das Alíquotas Progressivas. Revista Condomínio e etc., ano 2, $\mathrm{n}^{\circ} 7$, out/nov/dez 2000, págs. 12-13

14 Agravo de Instrumento $n^{\circ}$ 03339/2000, Rel. Juíza Maria Augusta Vaz de Figueiredo. Quarta Câmara Cível do Tribunal de Justiça do Rio de Janeiro. 


\section{Formas de correção}

A correção legislativa se dá através de emenda constitucional, lei complementar ou lei ordinária.

W. N. ESKRIDGE JR., no completo estudo sobre o tema, "Overriding Supreme Court Statutory Interpretation Decisions", de leitura obrigatória, esclarece que a correção ocorre quando o Congresso reage e modifica conscientemente uma interpretação judicial. ${ }^{15}$

Nesse caso, a atividade do legislador implica no "radical repúdio à interpretação judicial, pela edição de norma intencionalmente contrastante com a jurisprudência e na retificação da norma anterior, que, por ambigüidade ou falta de clareza, tenha levado o Judiciário a adotar interpretação incompativel com os pressupostos doutrinários da matéria." 16

Prima facie, pode parecer que a atividade do Congresso acarreta no controle ativo de um Poder do Estado sobre o outro.

Para CANOTILHO, trata-se de combinação de Poderes ${ }^{17}$. Para A. HAMILTON, J. JAY e J. MADISON, autores de $O$ Federalista, um verdadeiro sistema de pesos e contrapesos. ${ }^{18}$

DIOGO DE FIGUEIREDO MOREIRA NETO, no seu brilhante artigo "Interferências entre Poderes do Estado",19 vaticina que quando determinado Poder, dentro do exercício do desempenho de suas funções, tem o condão de sustar ou desfazer atos praticados, por um outro, resta caracterizado o chamado controle de correção. ${ }^{20}$

15 ESKRINDGE JR., W.N.. Overriding Supreme Court Statutory Interpretation Decisions: The Yale Law Journal 101 (2) (331-455, 1991)

16 TORES, Ricardo Lobo. A Integração entre a Lei e a Jurisprudência em Matéria Tributária: Cadernos de Direito Tributário e Finanças Públicas, Sâo Paulo: Revista dos Tribunais, ano 1, n. 3, abril-julho, p. 12, 1993.

17 CANOTILHO, José Joaquim Gomes. Direito Constitucional, Livraria Almeida, Coimbra, 1986, $4^{\text {a }}$ ed., pág. 195.

18 HAMILTOM, A.; JAY, J.; MADISON, J. The Federalist. n. 51, 1788.

19 MOREIRA NETO, Diogo de Figueiredo. Interferências entre Poderes no Estado: Revista de Informação Legislativa, ano 26, n. 103, jul/set 1989.

20 Idem, pág. 19:

"São exemplos de controle de correção atribuídos ao Legislativo, entre outros, os seguintes: o julgamento dos responsáveis em caso de ilegalidade de despesa ou irregularidade de contas (Art. 71, VIII), a rejeição, expressa ou tácita, de medida provisória editada pelo Presidente da República (Art. 62, parágrafo único) e a suspensão do estado de defesa, de intervenção federal e do estado de sítio (Art. 49, IV, in fine).

A correção, em outros casos, poderá ser parcial, deixando intacto o ato, suspendendo apenas sua execução (exeqüibilidade), como nas hipóteses de sustação dos atos normativos do Poder Executivo que exorbitem do poder regulamentar ou dos limites de delegaçāo legislativa (Art. 49, V), na de sustação de atos administrativos pelo Tribunal de Contas (Art. 71, X), na de sustação de contratos pelo Congresso Nacional (Art. $71, \S 1^{\circ}$ ) e na suspensão de execução, no todo ou em parte, de lei declarada inconstitucional por decisão definitiva do STF, esta a cargo do Sendo Federal (Art. $52, \mathrm{X})$. 
"Pela correção, realiza-se a mais drástica das modalidades de controle, cometendo-se ao Poder interferente a competência constitucional de suspender a execução, ou de desfazer, atos do Poder interferindo que venham a ser considerados viciados de legalidade ou de legitimidade." ${ }^{21}$

JOSÉ AFONSO DA SILVA, cuja doutrina merece ser seguida, entende que a interferência entre poderes é um instrumento de controle recíproco que visa buscar o equilíbrio necessário à realização do bem da coletividade, sendo indispensável para evitar o arbítrio e o desmando de um em detrimento do outro e, especialmente, dos governados. ${ }^{22}$

Será que a promulgação da EC 29/00 teve a finalidade de "buscar o equilíbrio necessário à realização do bem da coletividade", evitando, por conseguinte, o "arbítrio da decisão do STF" quanto a impossibilidade da fixação de alíquotas progressivas nos impostos reais?

JOACHIM LANG, ao discorrer sobre a plena constitucionalidade da correção legislativa, ressalva, expressamente, que a sua legitimidade é aferida nos casos em que o legislador é movido pelos seguintes objetivos:

a) manter o caráter sistêmico do direito tributário;

b) adequar a interpretação de normas específicas aos pressupostos dogmáticos em que se deve apoiar. ${ }^{23}$

Nesses e somente nesses casos, averba o substituto de KLAUS TIPKE na cátedra da Universidade de Colônia, a igualdade e a segurança jurídica não são prejudicadas com a correção, mormente quando a jurisprudência se apresenta de forma contraditória e incompleta ou se contrasta com os princípios gerais do direito. ${ }^{24}$

Dentro desse contexto, será trazido à baila o posicionamento da doutrina e jurisprudência, principalmente da CORTE CONSTITUCIONAL, sobre a progressividade de alíquotas nos impostos reais, objetivando seja aferida a presença de contradição ou contraste com princípios gerais de direito para que se possa concluir pela constitucionalidade — ou não - da multicitada EC 29/00.

Finalmente, como últimos exemplos, o controle de correçāo que se realiza pela mera declaração vinculativa de legalidade das contas do Presidente da República (Art. 49, IX, c/c. Art. 85, V e VI), a instauração de processo contra o Presidente da República e o Vice-Presidente da República e os Ministros de Estado (Art. 51, I) e o processamento e o julgamento, pelo Senado, do Presidente e o Vice-Presidente da República nos crimes de responsabilidąe e os Ministros de Estado nos crimes da mesma natureza conexo com aqueles (Art. 52, I) e o processamento e julgamento dos Ministros do Supremo Tribunal Federal, o Procurado-Geral da República e o Advogado-Geral da União, nos crimes de responsabilidade (Art. 52, II)."

21 Ibidem, p. 18.

22 SILVA, José Afonso. Curso de Direito Constitucional Positivo, $4^{\mathrm{a}}$ ed., Editora Revista dos Tribunais, 1987.

23 Apud TORRES, Ricardo Lobo. A Integração entre a Lei e a Jurisprudência em Matéria Tributária: Cadernos de Direito Tributário e Finanças Públicas, São Paulo: Revista dos Tribunais, ano 1, n. 3, abril-julho 1993, p. 16.

24 Idem, p. 16. 


\section{Breve e peculiar histórico corretivo constitucional brasileiro}

Antes da apresentação do tópico que versa sobre a jurisprudência do STF objeto da correção perpetrada pela EC 29/00, impende seja relembrado determinado dispositivo constitucional, previsto na Carta de 1937, provavelmente sem paradigma no direito comparado: a cassação da decisão judicial com eficácia retroativa e a preservação da lei inconstitucional. ${ }^{25}$

A justificativa utilizada à época para legitimar a utilização do controle de normas constitucionalizado era fundada na impossibilidade de se confiar a um órgão que não se origina do povo o controle do governo. Tal entendimento era capitaneado pelo ilustre FRANCISCO CAMPOS, cujo texto publicado versando sobre as Diretrizes Constitucionais do Novo Estado Brasileiro é de leitura obrigatória, merecendo, portanto, sua parcial transcrição:

"Não me parece essencial ao Poder Judiciário a prerrogativa de declarar a inconstitucionalidade das leis ou de recusar-lhes a execução com fundamento na sua incompatibilidade com a carta constitucional. Para que se pudesse considerar como essencial essa prerrogativa, seria indispensável que sem ela não se pudesse conceber a existência do Poder Judiciário. (...)

A modificação introduzida pela Constituição de 10 de novembro teve por fim repor na Nação controle do governo, submetendo-o ao juízo do povo, ao qual deve ficar livre a opção quando se tratar de por em movimento o mecanismo constitucional no sentido de serem realizados os grandes fins de ordem pública e geral, em relação aos quais o pronunciamento definitivo não pode deixar de caber ao povo. É a passagem do governo dos cenáculos para o governo do povo.

A faculdade de interpretar final e conclusivamente a Constituição, só se justificaria atribuí-la em regime democrático ao Poder Judiciário se o método jurídico fosse de natureza puramente lógica ou dedutiva. A função judiciária seria, então, puramente passiva, a interpretação limitando-se apenas a tornar explícito o conteúdo da lei.

Tais postulados são, porém, hipóteses contrárias à realidade. Nem o método jurídico é puramente lógico, nem o pensamento jurídico é puramente objetivo. A interpretação, por sua vez, longe de ser passiva e neutra, é um processo de criação ou de elaboração ativa. Quando a lei a ser interpretada é a Constituição, a generalidade, a amplitude, a compreensão da matéria

25 "Art. $96-$

Parágrafo único - No caso de ser declarada a inconstitucionalidade de uma lei que, a juízo do Presidente da República, seja necessária ao bem estar do povo, à promoção ou defesa de interesse nacional de alta monta, poderá o Presidente da República submetê-la novamente ao exame do Parlamento; se este a confirmar por dois terços de votos em cada uma das Câmaras, ficará sem efeito a decisão do Tribunal." 
abre um vasto campo à contribuição do intérprete que, embora animado da maior boa fé, não pode deixar de verter em termos da sua filosofia, pessoa ou da sua concepção da vida problemas do maior interesse vital para todo o mundo e em torno de cuja expressão, por mais precisa que seja, não pode deixar de existir um halo de indeterminação propicio às opções do temperamento, do caráter ou da vontade.

Nestas condiçōes atribuir a supremacia ao judiciário é atribuí-la à filosofia dos juizes. Em se tratando de interesses nacionais, dos grandes poderes do governo e dos grandes fins públicos a que o governo se destina, é certamente, mais democrático sendo mais acertado, preferir à opção e a filosofia da Nação filosofía e à filosofia e à opção dos juizes." 26

CELSO RIBEIRO BASTOS, no seu festejado Curso de Direito Constitucional, ao comentar a função dupla do referido instituto, assevera que a lei confirmada ganhava, assim, a força de uma Emenda Constitucional. ${ }^{27}$

Mas não é só. A mesma Carta de 1937 contemplava no seu art. 180 a possibilidade do Presidente da República expedir decretos-lei sobre todas as matérias da competência legislativa da União enquanto não se reunir o Parlamento Nacional ${ }^{28}$. Daí porque, o próprio "rei ditador" aproveitando-se da interpretação cominada dos citados arts. 96 e art. 180 baixou o célebre Decreto-Lei 1.564, de 05.09.1939, que acabou por suspender decisões judiciais, verbis:

"Decreto-Lei 1.564 - de 05.09.1939

Confirma os textos de lei, decretados pela Uniāo, que sujeitaram ao imposto de renda os vencimentos pagos pelos cofres públicos estaduais e municipais. O Presidente da República, usando da atribuição que lhe confere o art. 180 da Constituição, e para os efeitos do art. 96, parágrafo único.

Considerando que o STF declarou a inconstitucionalidade da incidência do imposto de renda, decretado pela União no uso de sua competência privativa, sobre os vencimentos pagos pelos cofres públicos estaduais e municipais.

Considerando que esta decisão judiciária não consulta o interesse nacional e o princípio da divisāo eqüitativa de ônus no imposto.

Decreta:

Artigo único. São confirmados os textos de lei, decretados pela União, que sujeitaram ao imposto de renda os vencimentos pagos pelos cofres públicos estaduais e municipais: ficando sem efeito as decisões do Supremo Tribunal

26 CAMPOS, Francisco. Diretrizes Constitucionais do Novo Estado Brasileiro. RF 415/417, jan/mar. 1938. V. 73, p. 229.

27 BASTOS, Celso Ribeiro. Curso de Direito Constitucional, $18^{2}$ ed., Editora Saraiva, 1997, p. 63.

28 “Art. 180 - Enquanto não se reunir o Parlamento Nacional, o Presidente da República terá o poder de expedir decretos-leis sobre todas as matérias da competência legislativa da União." 
Federal e de quaisquer outros tribunais e juizes que tenham declarado a inconstitucionalidade desses mesmos textos.

Rio de Janeiro, 05 de setembro de 1939, 118.0 da Independência de 51.0 da República.

Getulio Vargas - Francisco Campos - A. de Souza Costa"

Desafiadoramente preciso foi o voto à época proferido pelo então Ministro CARLOS MAXIMILIANO, no julgamento do MS 623, onde se discutia exatamente a eficácia da decisão confirmativa baixada pelo Presidente da República, nos termos do Decreto-Lei supra transcrito, verbis:

"A Constituição de 1891 incorporou o Brasil ao sistema democrático americano - o do governo de leis em vez de governo de homens: entre nós, como nos Estados Unidos e na República Argentina, a cúpula do regime achava-se na Corte Suprema: por isto, os grandes palestrantes da terra de Jefferson, nas cerimônias solenes, davam a frente aos juizes do pretório excelso, em republicana e belissima homenagem à soberania da Justiça. Os tribunais reviam e anulavam, aliás com discreta reserva, as leis e atos contrários ao espírito do código fundamental.

$O$ Chile constituía notória exceção, porque se inclinara para a onipotência parlamentar, à francesa, porém evoluiu no sentido generalizado no continente: naquela república, a reforma constitucional de 1925 investiu o Judiciário da prerrogativa outorgada pelo estatuto norte-americano, "o mais perfeito do mundo", segundo o conceito de Barbaho dos Andes, o hábil comentador do novo código básico, o professor Guerra, morto tragicamente em Valparaíso na semana em que eu visitava aquela encantadora cidade de veraneio.

Notável coincidência, no mesmo ano de 1925, famoso aresto do Tribunal Supremo da Alemanha (Reichsgericht), em 04 de novembro proclamou a autoridade da magistratura para declarar inválidos, por inconstitucionais, diplomas legislativos; assim foi decidido, apesar de não haver na Constituição de Weimar preceito expresso a tal respeito. Manifestou-se na terra de Frederico, à semelhança do que ocorrera, sobre o mesmo assunto, na pátria de Washington, a ação criadora da jurisprudência.

O estatuto brasileiro de 1937, no art. 96, transferiu, em tal esfera, a supremacia ao Legislativo, quando provocado pelo Presidente: julgada inconstitucional, uma lei, posterior decreto atua e prevalece como vitoriosos embargos infringentes ao aresto supremo. De tal prerrogativa do Parlamento usou o Sr. Presidente da República, escudado no art. 180 da Constituição, a propósito da incidência de imposto federal sobre os proventos de funcionários locais, porque sobrepondo a lei a interesse ou rivalidade individual ou de classe, os membros do pretório mais alto haviam declarado os serviços, e, conseqüentemente, os servidores dos Estados, isentos de tributos que eles, Ministros togados, pagam, sem recalcitrar nem discutir. 'Qual a diretriz futura a predominar nos pretório, em face da resolução 
presidencial? Não posso recorrer ao apoio precioso do Direito Comparado: porque a providência constitucional brasileira, consiste em reformar sentenças por meio de decreto não encontra similar ou paradigma em país nenhum do orbe terráqueo'. Recorro a outra fonte: os precedentes, em casos análogos. Vigorante o sistema generalizado na América, embora o Judiciário apenas decidisse em espécie e a sentença final só abrigasse no caso em apreço, Presidente e Congresso, em obediência ao princípio da harmonia dos poderes, dali por diante se abstinham de agir ou deliberar contra as conclusões do aresto supremo. Pela mesma razão, agora, atribuída à Legislatura a antiga preeminência da Corte excelsa, esta não mais conhecerá de igual inconstitucionalidade. Seria aliás, irrisório estar a proferir acórdãos platônicos, arestos por lei destituidos de exeqüibilidade. Prevalecerá no alto pretório o inelutável, embora murmurando os seus membros o"e pur si muove", de Galileu. Em conclusão: pelo menos no meu conceito, desagradável incidente para o qual confluiram, durante uma quinzena, as vistas sobressaltadas dos juristas nacionais, está definitivamente encerrado. No tocante à hipótese em apreço, eu julgo prejudicados os dois recursos: porque o Dec. Lei 1.564, de 05.09.1939, posterior à sentença concessiva do mandado de segurança, explicitamente a tornou sem efeito." (RF 82. P. $298(300)$ )

GILMAR FERREIRA MENDES ${ }^{29}$ conclui que esse instituto possui referência provável na experiência constitucional americana, citando, para tanto, a obra de KARL LOEWENSTEIN sobre direito constitucional americano, segundo o qual "um outro mecanismo de limitação do poder da Corte Suprema assenta-se na possibilidade de nulificação dos efeitos da decisão mediante lei de caráter corretivo (Korrigierendes Gesentz). Trata-se apenas de casos em que o Congresso manifesta divergência com interpretação conferida à norma pela Corte Suprema. Esse mecanismo não se aplica às hipóteses de declaração de inconstitucionalidade de índole formal ou material. Nesses casos, apenas uma reforma constitucional pode mostrarse apta a solver o conflito, como já ocorreu após a declaração de inconstitucionalidade da lei de imposto de renda (Bundesein-kommenstuer) Pollock v. Farmers Loan \& Trust. Co., 158 U.S. 601, 1898) através da promulgação da XVI Emenda (1913). Esses casos raros, uma vez que o Congresso apenas consegue utilizar-se do poder de emenda contra decisão da Suprema Corte em hipótese de inequívoco relevo." (LOEWENSTEIN. Verfassungsrecht und Verfassungspraxis der Vereinigten Staaten. 1959, p. 429)

De fato, a Emenda XVI à Constituição Americana foi consequiência direta da decisão da Suprema Corte no caso Pollock v. Farmers Loan \& Trust Co., 157 U.S., 429 (1895), 158 U.S. 601 (1895), como anotado por EDWARD CORWIN: " $a$

29 MENDES, Gilmar Ferreira. O Poder Executivo e o Poder Legislativo no Controle de Constitucionalidade: Cadernos de Direito Tributário e Finanças Públicas, São Paulo: Revista dos Tribunais, n. 20, 1997. 
ratificação desta emenda foi conseqüência direta da decisão de 1895, pela qual uma Corte Suprema muito dividida julgou inconstitucional a tentativa do Congresso, do ano anterior, de tributar uniformemente os rendimentos em todo os Estados Unidos. Um imposto de renda derivado de propriedade, declarou a Corte, era "imposto indireto" que o Congresso, de acordo com os termos do art. I, seção 2, cláusula 3, e seção 9, claúsula 4, só podia lançar obedecendo a regra da proporcionalidade, segundo a população" (EDWARD S. CORWIN. A Constituição Norte-Americana. Rio de Janeiro, 1986, p. 336). ${ }^{30}$

Contudo, como bem observa LOEWENSTEIN, não se cuidou propriamente de "rejeição" da decisão da Corte Suprema (o que representaria a supressão da independência do Poder Judiciário), mas de posterior reforma constitucional, resguardando-se íntegra a decisão da Corte Suprema. ${ }^{31}$

E no particular, qual a jurisprudência que o legislador pretende corrigir?

\section{O STF e a impossibilidade de alíquotas progressivas nos impostos reais}

Dispõe o art. $145, \S 1^{\circ}$ da Constituição Federal que "sempre que possivel, os impostos terão caráter pessoal e serão graduados segundo a capacidade econômica do contribuinte".

Também conhecido como princípio da capacidade contributiva é dividido, segundo a melhor doutrina capitaneada por RICARDO LOBO TORRES,,$^{32} \mathrm{em}$ quatro sub princípios: proporcionalidade, progressividade, seletividade e personalização.

Pois bem. A quaestio iuris é saber se o imposto real que recai sobre as coisas (res: coisa), ou seja, sobre bens imóveis (IPTU; ITBI) e bens móveis (IPVA) podem ter alíquotas progressivas, ex vi art. $145, \S 1^{\circ}$ da Constituição Federal.

Para o E. SUPREMO TRIBUNAL FEDERAL a resposta é negativa. Como dito alhures, adota a Corte Extraordinária a distinção clássica entre impostos pessoais (que recaem sobre as pessoas) e reais (sobre bens), rechaçando em iterativa jurisprudência a compatibilidade desta técnica (progressividade) em face de impostos, cuja base de cálculo seja o preço de venda, este notadamente proporcional.

Nesse contexto, impende que seja transcrito o voto-condutor do eminente Ministro MOREIRA ALVES, proferido no leading case que declarou inconstitucional a progressividade de alíquotas do Imposto sobre a Propriedade Predial e Territorial Urbana - IPTU ${ }^{33}$ :

"(...)

3. Reza o $\S 1^{\circ}$ do artigo 145 :

30 Idem, p. 22.

31 Ibidem, p. 23.

32 TORRES, Ricardo Lobo. Tratado de Direito Constitucional Financeiro e Tributário, vol. III, Rio de Janeiro: Renovar, 1999, p. 436.

33 RE n 153771-0/MG, Relator Ministro MOREIRA ALVES, STF, D.J. de 05.09.97. 
'\$ $1^{\circ}$. Sempre que possível, os impostos terão caráter pessoal e serão graduados segundo a capacidade econômica do contribuinte, facultado à administração tributária, especialmente para conferir efetividade a esses objetivos, identificar, respeitando os direitos individuais e nos termos da lei, o patrimônio, os rendimentos e as atividades econômicas do contribuinte.'

Desse dispositivo decorre que a 'Constituição', adotando a distinção clássica segundo a qual os impostos podem ter 'caráter pessoal' ou 'caráter real' (é a classificação que distingue os impostos em pessoais e reais), visa a que os impostos, sempre que isso seja possivel, tenham o caráter pessoal, caso que serão graduados - e um dos critérios de graduação poderá ser a progressividade - segundo a capacidade econômica do contribuinte.

Por outro lado, em face desse dispositivo, não se pode pretender que a expressão "sempre que possivel" se refira apenas ao caráter pessoal do imposto, e que, por isso, o princípio da capacidade contributiva seja aplicável a todos os impostos ainda quando não tenham caráter pessoal, como sustentam Américo Lacombe e José Maurício Conti, citados no voto do eminente relator. De feito, a parte final do dispositivo em causa repele essa conclusão, porque a Constituição atribui à administração tributária a faculdade de identificar o patrimônio, os rendimentos e as atividades econômicas do contribuinte, "especialmente para conferir efetividade a ESSES OBJETIVOS", ou seja, ao objetivo de que os impostos, se possivel, tenham caráter pessoal e ao de que esses impostos com caráter pessoal sejam graduados segundo a econômica do contribuinte, certo como é que essa faculdade de identificação só tem sentido quando se trata de imposto de caráter pessoal, ou seja - na definição de GIANINI, "aqueles que alcançam o conjunto de rendimentos ou de bens do contribuinte, ou também uma parte destes, mas enquanto dizem respeito a uma dada pessoa, levando em conta, em medida mais ou menos ampla, as suas condições". O mesmo não ocorre, evidentemente, com os impostos de caráter real que — também na definição de GIANINI - são os que "alcançam bens singulares ou rendimentos ou também grupos de bens ou de rendimentos, considerados na sua objetividade, sem levar em cota a condição pessoal do sujeito passivo do imposto" ${ }^{34}$.

Prossegue o eminente decano sustentando seu entendimento, apoiando-se, para tanto, em vasta doutrina repelidora da progressividade nos impostos reais:

"Por isso mesmo, VICTOR UKMAR tratando do princípio constitucional da igualdade tributária no tocante à capacidade contributiva, se refere ao "EVIDENTE ABSURDO DE ALÍQUOTAS PROGRESSIVAS PARA OS IMPOSTOS REAIS". Igualmente VINCENZO CARULLO acentua: "Natural-

34 RE n 153771-0/MG, Relator Ministro MOREIRA ALVES, STF, D.J. de 05.09.97. p. 529-530. 
mente, não queremos dizer - nem o poderemos - que todos os impostos indistintamente devem ser progressivos, porque sabemos como isso seria IMPOSSÍVEL ou cientificamente errado: porque bem sabemos que A PROGRESSÃO NÃO CONDIZ COM OS IMPOSTOS DIRETOS REAIS e pode encontrar só inadequada aplicação nos impostos sobre consumos e nos impostos indiretos em geral". No mesmo sentido, ZINGALLI COCIVERA que dá como uma das características do imposto real a de ele "não pode ser organizado em forma progressiva (sendo a progressividade das alíquotas fundadas sobre o conceito de capacidade contributiva)". Essa também a posição de BERLIRI "Aliás, num sistema inspirado em critérios de progressividade é natural que a imposição tenha caráter pessoal e não real". Também na Suiça, BLUMENSTEIN acentua que " a distinçāo entre impostos subjetivos e objetivos (pessoais e reais) decorre do fato de que para determinados tipos pode prestar-se atenção à capacidade econômica pessoal do sujeito, enquanto para outros conta só a existência de um determinado objeto de imposto".

Ressalte-se, ad argumentandum tantum, que os demais Ministros acompanharam in totum tal entendimento, merecendo destaque, para não massacrar o leitor, os seguintes pronunciamentos:

Ministro MAURÍCIO CORREA:

"O caso especifico de que ora se cuida é exatamente o de imposto predial, que pela sua própria natureza é um tributo real, incidente sobre o imóvel urbano, não recaindo sobre a pessoa, como é o caso do imposto de renda e de outras exações similares" 35.

\section{Ministro ILMAR GALVÃO:}

"O critério, como se vê, é de natureza objetiva, certamente porque se está diante de um tributo, não de natureza pessoal, cuja alíquota possa variar em função das condições econômicas do proprietário do bem, na forma preconizada no art. $145, \S I^{\circ}$, da $C F$, parte final, mas de natureza real ". ${ }^{36}$

\section{Ministro NÉRI DA SILVEIRA:}

"Cuidando-se de IPTU, cumpre, por primeiro, ter presente sua natureza real' 37 .

Corroborando com o ora esposado, recentemente foi publicado (D.J. 31.03.2000) o acórdão proferido pela SESSÃO PLENÁRIA DA CORTE CONSTI-

35 RE n ${ }^{\circ}$ 153771-0/MG, Relator Ministro MOREIRA ALVES, STF, D.J. de 05.09.97. p. 543.

$36 \mathrm{RE} \mathrm{n}^{\circ}$ 153771-0/MG, Relator Ministro MOREIRA ALVES, STF, D.J. de 05.09.97. p. 551 .

37 RE n 153771-0/MG, Relator Ministro MOREIRA ALVES, STF. D.J. de 05.09.97. p. 566. 
TUCIONAL onde, por unanimidade de votos, foi afastada a progressividade de outro imposto real, in casu o ITBI, verbis:

“CONSTITUCIONAL. TRIBUTÁRIO. IMPOSTO DE TRANSMISSÃO DE IMOUVEIS, INTER VIVOS - ITBI. ALIQUUTAS PROGRESSIVAS. C.F. art. 156, II, § $2^{\circ}$. Lei $n^{\circ} 11.154$, de 30.11.91, do Município de São Paulo, SP. I - Imposto de Transmissão de Imóveis, Inter Vivos - ITBI: alíquotas progressivas: a Constituição Federal não autoriza a progressividade das alíquotas, realizando-se o princípio da capacidade contributiva proporcionalmente ao preço de venda.

$I I-R$.E. conhecido e provido". ${ }^{38}$

Ad summam, cediço é o entendimento do Pleno do E. STF que a única progressividade admitida pela $\mathrm{CF} / 88$ é aquela prevista no art. $182, \S 4^{\circ}$, II, verbis:

“Art. $182-\ldots$

$\$ 4^{\circ}$ - É facultado ao Poder Público municipal, mediante lei específica para a área incluída no plano diretor, exigir, 'nos termos da lei federal', do proprietário do solo urbano 'não edificado', subutilizado ou não utilizado, que promova seu adequado aproveitamento, sob pena, sucessivamente, de: ...

II - imposto sobre a propriedade predial e territorial urbana 'progressivo no tempo'.

(g.n.)

Nesse contexto, merece ser ressaltado as seguintes conclusões acerca da exegese do transcrito artigo constitucional:

a) inexiste a lei federal exigida pelo Texto Mater, posto que não editada, conforme asseverou o eminente Ministro CELSO DE MELLO no multicitado RE 153.771-0, verbis:

"A ausência de lei federal a que se refere expressamente o art. 182, $\S 4^{\circ}$ - lei federal que ainda não foi editada - atua, como fator de progressividade do IPTU, como fator inibitório da instituição, por qualquer Município, do imposto predial e territorial urbano, com alíquotas progressivas."

b) a progressividade no tempo tem caráter notadamente extrafiscal, parafraseando RICARDO LOBO TORRES, "objetivando certos efeitos na área econômica e social, que transcendem a mera finalidade de fornecer recursos para atender às necessidades do tesouro". ${ }^{39}$ Em outras palavras, se já tivesse sido editada a lei federal

38 RE $n^{\circ}$ 234.105-3/SP, Relator Ministro CARLOS VELLOSO, Tribunal Pleno, STF, decisão unânime, D.J. de 31.03.2000.

39 TORRES, Ricardo Lobo. Tratado de Direito Constitucional Financeiro e Tributário, vol. III, Rio de Janeiro: Renovar, 1999. 
a que alude o dispositivo, os Municípios poderiam fixar alíquotas que aumentariam a cada ano, objetivando "forçar" o contribuinte a dar uma utilização ao seu terreno, evitando a especulação imobiliária e cumprindo a denominada função social da propriedade.

Logo, impossível a confusão entre o caráter fiscal pretendido pela EC 29/00 e o caráter extrafiscal inserido na $\mathrm{CF} / 88$.

Repita-se: todos os Ministros que compõe a Suprema Corte comungam do mesmo entendimento. Tamanha a certeza dessa jurisprudência que atualmente os membros da mais Alta Corte vêm negando seguimento aos recursos extraordinários interpostos pelos Municípios face ao confronto desses com a sua jurisprudência consolidada, ex vi art. 557 do CPC, verbis:

\section{“Objeto: Tributário. IPTU. Progressividade.}

O recurso contraria a jurisprudência predominante do STF:

"A única hipótese constitucional de progressividade das alíquotas da IPTU é a extrafiscal, destinada a assegurar o cumprimento da função social da propriedade" (RREE 194.036; 204.827; 199.969; 202.261; 198.506; 153. 771)

Nego seguimento (art. $21, \S 1^{\circ}$, RISTF; art. 38, Lei $8.038 / 90$ e art. 557, do CPC). ${ }^{40}$

\section{MINISTRO NELSON JOBIM}

“Alega o Município de São Paulo ser legítima a progressividade de Imposto Predial e Territorial Urbano aplicada em função do valor venal do imóvel. 2. A jurisprudencia desta Corte, no tema em debate, concluiu que, sendo o IPTU espécie tributária de natureza real, a capacidade econômica do contribuinte não pode ser utilizada como critério para a sua cobrança $\left(\mathrm{RE} \mathrm{n}^{\circ}\right.$ 153.771. RTJ 1621726).

3. Nessa mesma linha, o Plenário desta Corte entendeu inconstitucional o art. $7^{\circ}$ da Lei $n^{\circ} 6.989156$ do Município de São Paulo, com redacão que lhe deu a Lei $n^{\circ} 10.921190$, porque instituiu alíquotas progressivas para a cobrança do IPTU em razão da imóvel. Essa disposicão legal afrontar a regra do artigo 182. $\S 4^{\circ}$, II da Constituicão Federal, que condiciona a prerrogativa prevista no artigo $156, \S 1^{\circ}$ da Carta à edição de legislação federal específica e à utilização do fator tempo para a graduação do tributo (RE 204.827, DJU 25/04/97, p. 15.213).

Ante o exposto, com base no artigo $21, \S 1^{\circ}$ da RISTF, nego seguimento ao agravo

Intime-se."41

40 Agravo de Instrumento n 234.893-1; Arte: Município de São Paulo; Agrdo: ELETROPAULO — Eletricidade de São Paulo S/A, Relator: Ministro Nelson Jobim, publicado DJ em 29.03.1999 4 Agravo de Instrumento n 243.970-7, Agte: Município de São Paulo; Agdo: Condutec Empreendimentos e Participações S/C, Relator Ministro Maurício Corrêa, publicdo no DJ de 10.06.2000. 


\section{MINISTRO MAURÍCIO CORRÊA}

Assim sendo, conforme amplamente visto e revisto, pode-se afirmar, sem erro, que a jurisprudência da mais Alta Corte do país não se apresenta de forma contraditória ou incompleta. Ao contrário, posto que encampada por unanimidade pelos Ministros-membros.

Por outro lado, a exaustiva jurisprudência referida não contrasta com os princípios gerais do direito, mormente quando a doutrina nacional e alienígena ${ }^{42}$ comunga da mesma hóstia ao afastar a progressividade de alíquotas do IPTU, imposto real, notadamente proporcional.

Tendo em vista as considerações apresentadas no presente estudo, merece seja abaixo respondida a quaestio iuris proposta: seria, pois, constitucional a EC 29/00?

\section{Conclusões}

a) ocorre contradição entre duas ou mais normas quando estas são incoerentes, antinomicas ou incompatíveis entre si;

b) nos casos em que a antinomia é meramente aparente, torna-se desnecessária a correção, posto que sanável mediante ponderação entre os princípios aplicáveis, prevalecendo aquele com maior peso sem, entretanto, poder se concluir pela superioridade de qualquer deles;

c) é exatamente no campo das contradições de princípios, para $\mathrm{BOBBIO}^{43}$ denominado de antinomia de valores, onde as fórmulas clássicas ${ }^{44}$ não resolvem o conflito, que se torna empolgante o enfrentamento da quaestio pelo intérprete;

d) a promulgação da EC $29 / 00$ que possibilita aos Município a instituição de alíquotas progressivas de IPTU em razão do valor, localização e uso do imóvel, constituindo-se uma forma de correção legislativa da jurisprudência do E. SUPREMO TRIBUNAL FEDERAL, a qual, por unanimidade de votos de seus membros,

42 GIANINI, Istituzioni di Diritto Tributario, reimpressão da $9^{a}$ ed., p. 159, Milano: Dott A Giuffrè Editore, 1974.

UKMAR, Victor. Princípios Comuns de Direito Constitucional Tributário, trad. Marco Aurélio Greco, São Paulo: Revista dos Tribunais, p. 82, 1976. CARULLO, Vicenzo. La Costituzione della Repubblica Italiana, Bologna: Dott. Cesare Zuffi-Editore, p. 184, 1950. COCIVERA, Zingali apud DOTT, A. Principi di Diritto Tributário, v. I, nota 60, Milano: Giuffrè Editore, ps. 253/254, 1974. BERLIRI. Principi di Diritto Tributario, v. I, $2^{2}$ ed., ps. 268/269, Milano: Giuffrè Editore, 1967. BLUMENTEIN. Sistema di Dirito delle Imposte. Trad. FRANCESCO FORTE, § 10, II, 2, DOTT.A. Giuffré Editore, Milano, 1954.

43 BOBBIO, Norberto. Des Critères pour les Antinomie : Les Antinomies... Chaim, Perelman,, p. 240.

44 Nesses casos, o interprete, e, no particular, o juiz, utiliza-se de formas clássicas para a sua superação, v.g. prevalência da norma posterior sobre a anterior de mesma natureza (lex posterior derogat priori), preferência da norma de nível superior em relação à de nível inferior (lex superior derogat priori), e predominância da norma especial sobre a de caráter geral (lex specialis derogat generali). 
já teve a oportunidade de afastar a técnica da progressividade em face de impostos reais, tais como o IPTU e ITBI ${ }^{45}$

e) considerando-se que a técnica da progressividade vem estampada no art. 145 , $\S 1^{\circ}$ da Carta Magna, o qual dispõe sobre o princípio da capacidade contributiva, torna-se, no particular, um conflito entre o referido princípio e o da igualdade;

f) a opção do legislador pela adoção de critérios progressivos ou regressivos nos impostos sobre o patrimônio, notadamente proporcionais, fere a igualdade ${ }^{46}$, uma vez que contribuintes que se encontram na mesma situação, v.g. proprietários de imóveis com idêntico valor venal, poderão, ex vi EC 29/00, ficar sujeitos a carga tributária diferenciada em função da localização e uso do imóvel;

g) a promulgação da EC 29/00 implica, inegavelmente, no "radical repúdio à interpretação judicial, pela edição de norma intencionalmente contrastante com a jurisprudência e na retificação da norma anterior" ${ }^{47}$, todavia, no particular, inexistia ambigüidade ou falta de clareza na norma pretérita que pudesse ter ensejado o judiciário a adotar interpretação incompatível com os pressupostos doutrinários da matéria;

h) correta, portanto, a doutrina de JOSÉ AFONSO DA SILVA ao asseverar que a interferência entre poderes, decorrente da correção legislativa, deve (ou, deveria) buscar o equilíbrio necessário à realização do bem da coletividade, posto que visa evitar o arbítrio e o desmando de seu Poder em detrimento do outro ${ }^{48}$;

i) para JOACHIM LANG, a legitimidade da correção ocorre quando o legislador objetiva manter o caráter sistêmico do direito tributário e adequar a interpretação de normas específicas aos pressupostos dogmáticos em que se deve apoiar ${ }^{49}$;

j) na verdade, o que pretendeu o legislador constituinte derivado não foi a " busca do equilíbrio à realização do bem coletivo", sugerido por JOSÉ AFONSO DA SILVA $^{50}$; nem manter o caráter sistêmico do direito tributário ou adequar a interpretação de normas específicas aos pressupostos dogmáticos, nas palavras de $\mathrm{LANG}^{51}$; tão pouco corrigir ambiquiidade ou falta de clareza da legislação pretérita

$45 \mathrm{RE} \mathrm{n}^{\circ}$ 153771-0/MG, Relator Ministro MOREIRA ALVES, DJ de 05.09.97, STF (leading case IPTU); RE 234.105-3/SP, Relator Ministro CARLOS VELLOSO, Tribunal Pleno, unânime, DJ de 31.03.2000 (leading case ITBI).

46 TORRES, Ricardo Lobo. Tratado de Direito Constitucional, Financeiro e Tributário, v. III, Rio de Janeiro: Renovar, 1999, p. 335.

47 TORES, Ricardo Lobo. A Integração entre a Lei e a Jurisprudência em Matéria Tributária: Cadernos de Direito Tributário e Finanças Públicas, Sâo Paulo: Revista dos Tribunais, ano 1, n. 3, abril-julho, p. 12, 1993.

48 SILVA, José Afonso. Curso de Direito Constitucional Positivo, $4^{\mathrm{a}}$ ed., Editora Revista dos Tribunais, 1987.

49 TORRES, Ricardo Lobo. A Integração entre a Lei e a Jurisprudência em Matéria Tributária: Cadernos de Direito Tributário e Finanças Públicas, São Paulo: Revista dos Tribunais, ano 1, n. 3, abril-julho 1993, p. 16.

50 SILVA, José Afonso. Curso de Direito Constitucional Positivo, $4^{\mathbf{a}}$ ed., Editora Revista dos Tribunais, 1987.

51 TORRES, Ricardo Lobo. A Integração entre a Lei e a Jurisprudência em Matéria Tributária: 
que tenha levado o STF a adotar interpretação incompatível com os pressupostos doutrinários da matéria, conforme escólio de RICARDO LOBO TORRES ${ }^{52}$; mas sim perpetrar uma tradição de direito positivo brasileiro em instituir "ilegalidades eficazes", cujo objetivo é, notadamente, locupletar o fisco sob o manto do sacrifício coletivo para o bem geral (nesse sentido o autor do presente trabalho já se manifestou no artigo "Taxas: Origem, Características, Competência para Instituição, Preço Público, Capacidade Contributiva e Extrafiscalidade", publicado na Revista IberoAmericana de Direito Público) $)^{53}$;

k) a atitude do legislador ao promulgar a EC $29 / 00$ foi motivada, por tudo o exposto, pelo interesse meramente fiscalista, donde se conclui, curvando-se a firme corrente capitaneada por JOACHIM LANG, que a multicitada Emenda Constitucional é inconstitucional. ${ }^{54}$

Cadernos de Direito Tributário e Finanças Públicas, São Paulo: Revista dos Tribunais, ano 1, n. 3, abril-julho 1993, p. 16.

52 TORES, Ricardo Lobo. A Integração entre a Lei e a Jurisprudência em Matéria Tributária: Cadernos de Direito Tributário e Finanças Públicas, Sâo Paulo: Revista dos Tribunais, ano 1, n. 3, abril-julho, p. 12, 1993.

53 ANTONELLI, Leonardo Pietro. Taxas: Origem, Características, Competência para Instituição, Preço Público, Capacidade Contributiva e Extrafiscalidade. Revista Ibero-Americana de Direito Público, vol. I, Rio de Janeiro: América Jurídica.

"Todavia, o que reina no Brasil, principalmente em âmbito municipal - posto que o paradigma utilizado é a taxa de coleta de lixo e limpeza pública - TCLLP —, é a chamada "ilegalidade eficaz". Tal anomalia, que se jusitifica para muitos políticos como meio de arrecadação tributária, resulta do entrave que é o acesso ao judiciário pela população em geral e, do outro lado, a absurda coação imposta pelo Fisco em face do pobre (e somente estes) contribuintes inadimplentes.

Como exemplo, o Município do Rio de Janeiro que está em franca campanha publicitária no sentido de que o contribuinte tem a última chance de pagar seus débitos em atraso de IPTU, TCLLP e TIP, sob pena de execução fiscal, penhora e conseqüente leilão judicial do seu imóvel.

Ad absurdum, todos os três tributos supra citados, já foram declarados inconsticionais (IPTU em parte) pelo egrégio Supremo Tribunal Federal.

Em outras palavras, em vez de o contribuinte ser chamado a receber a restituição dos pagamentos indevidos, é executado e a cobrança ilegal continua a ocorrer, locupletando ilicitamente o Fisco sob o manto do "sacrifício coletivo para o bem geral".

Balela. Tudo balela."

54 LANG, Joachim apud TORRES, Ricardo Lobo. A Integração entre a Lei e a Jurisprudência em Matéria Tributária. Cadernos de Direito Tributário e Finanças Públicas, Editora Revista dos Tribunais. Ano 1, n. 3, abril-junho 1993, p. 15 e 16.

"O Prof. Joachim Lang, que substituiu o Prof. Kalus Tipke na cátedra da Universidade de Colônia, quando de sua aposentadoria, anota que é plenamente constitucional a correção legislativa, se vem para manter o caráter sistêmico do direito tributário e para adequar a interpretação de normas específicas aos pressupostos dogmáticos em que deve se apoiar; averba, ainda, que a igualdade e a segurança jurídica não são prejudicadas com a correção, se a jurisprudência se apresenta de forma contraditória e incompleta ou se contrasta com os princípios gerais do direito; a atitude do legislador só seria inconstitucional se motivada pelo interesse meramente fiscalista ou se tivesse por objetivo subverter o equilibrio entre os poderes do Estado.'" 
ANTONELLI, Leonardo Pietro. Iptu e a Inconstitucionalidade das Alíquotas Progressivas. Condomínio e Etc. Revista Trimestral da CIPA Administradora de Imóveis, ano 2, n. 7, p. out/nov/dez 2000.

ANTONELLI, Leonardo Pietro. Taxas: Origem, Características, Competência para Instituição, Preço Público, Capacidade Contributiva e Extrafiscalidade. Revista Ibero-Americana de Direito Público, vol. I, Rio de Janeiro: América Jurídica.

BASTOS, Celso Ribeiro. Curso de Direito Constitucional, $18^{\mathrm{a}}$ ed., Editora Saraiva, 1997, p. 63.

BERLIRI. Principi di Diritto Tributario, v. I, $2^{\text {a }}$ ed., ps. 268/269, Milano: Giuffrè Editore, 1967.

BLUMENTEIN. Sistema di Dirito delle imposte. Trad. FRANCESCO FORTE, § 10, II, 2, DOTT.A. Giuffré Editore, Milano, 1954.

BOBBIO, Norberto. Des Critères pour les Antinomie: Les Antinomies... Chaim, Perelman, p. 240.

CAMPOS, Francisco. Diretrizes Constitucionais do Novo Estado Brasileiro. RF 415/417, jan/mar. 1938. V. 73, p. 229.

CANOTILHO, José Joaquim Gomes. Direito Constitucional, Livraria Almeida, Coimbra, 1986, $4^{\text {a }}$ ed., pág. 195.

CARULlO, Vicenzo. La Costituzione della Repubblica Italiana, Bologna: Dott. Cesare Zuffi-Editore, p. 184, 1950.

COCIVERA, Zingali apud DOTT, A. Principi di Diritto Tributário, v. I, nota 60, Milano: Giuffrè Editore, ps. 253/254, 1974.

ESKRINDGE JR., W.N.. Overriding Supreme Court Statutory Interpretation Decisions: The Yale Law Journal 101 (2) (331-455, 1991).

GIANINI, Istituzioni di Diritto Tributario, reimpressão da $9^{\text {a }}$ ed., p. 159, Milano: Dott A Giuffrè Editore, 1974.

HAMILTOM, A.; JAY, J.; MADISON, J. The Federalist, n. 51, 1788.

MENDES, Gilmar Ferreira. O Poder Executivo e o Poder Legislativo no no Controle de Constitucionalidade: Cadernos de Direito Tributário e Finanças Públicas, São Paulo: Revista dos Tribunais, n. 20, p. 22-23, 1997.

MORAES, Bernardo Ribeiro. Compêndio de Direito Tributário, v. 1, Rio de Janeiro: Forense, 1999, p. 439.

MOREIRA NETO, Diogo de Figueiredo. Interferências entre Poderes no Estado: Revista de Informação Legislativa, ano 26, n. 103, jul/set 1989.

PIRES, Adilson Rodrigues. Contradições no Direito Tributário, Rio de Janeiro: Forense, 1999.

SILVA, José Afonso. Curso de Direito Constitucional Positivo, $4^{\mathrm{a}}$ ed., Editora revista dos Tribunais, 1987.

TORRES, Ricardo Lobo. A Integração entre a Lei e a Jurisprudência em Matéria Tributária: Cadernos de Direito Tributário e Finanças Públicas, Sâo Paulo: Revista dos Tribunais, ano 1, n. 3, p. 12/16, abril-julho 1993.

TORRES, Ricardo Lobo. Normas de Interpretação e Integração do Direito Tributário. Rio de Janeiro: Renovar, p. 44/240/335, 2000. 
TORRES, Ricardo Lobo. Prefácio: Contradições no Direito Tributário, Rio de Janeiro: Forense, 1999.

TORRES, Ricardo Lobo. Tratado de Direito Constitucional Financeiro e Tributário, vol. III, Rio de Janeiro: Renovar, 1999, p. 436.

UKMAR, Victor. Princípios Comuns de Direito Constitucional Tributário, trad. Marco Aurélio Greco, São Paulo: Revista dos Tribunais, p. 82, 1976. 


\section{Teoria e Prática do Direito Marítimo}

\section{Carla Adriana Comitre Gibertoni}

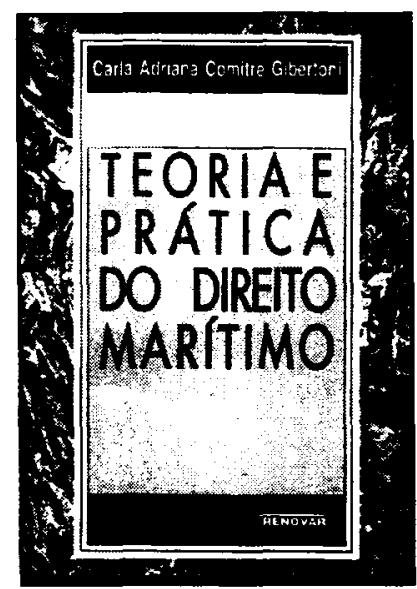

Nesta obra a autora apresenta informações atualizadas e indispensáveis sobre o assunto no âmbito nacional, tais como: a prática da navegação, o Tribunal Marítimo e suas decisões, os Acidentes e Fatos da Navegação, o Seguro Marítimo, o Transporte Marítimo e a responsabilidade civil e a Lei de modernização dos portos, que tanto interfere nas atividades portuárias.

Ref. 0183

Form. 14x21
Brochura 1998
508 págs.

\section{Tratado de Direito Comparado Introdução ao Direito Comparado \\ Leontin-Jean Constantinesco}

Com este trabalho, o autor procura justamente individualizar os critérios através dos quais inserir essa imagem fragmentária do Direito numa visão unitária que tente compreender o Direito na atual situação espaço-temporal. Não é mais possível continuar confundindo legislação alienígena com Direito Comparado.

Ref. 0182

Form. 14x21
Brochura 1998

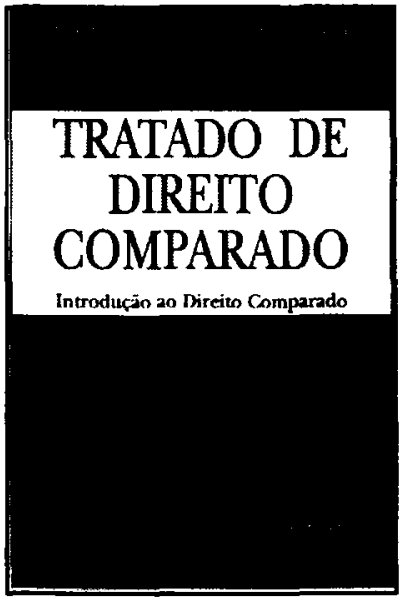

